\title{
Mathematical Model of Electric Vehicle Power Consumption for Traveling and Air-Conditioning
}

\author{
Seishiro Shibata and Tsuguhiko Nakagawa \\ Department of Thermal Engineering, Graduate School of Okayama Prefectural University, Okayama 719-1197, Japan
}

Received: December 01, 2014 / Accepted: December 31, 2014 / Published: March 31, 2015.

\begin{abstract}
In order to make maximum use of the EV (electric vehicle) battery, evaluating the remaining battery capacity and the power consumption is important. Evaluation method of the remaining battery capacity with accuracy has been proposed. Moreover, the evaluation method of the power consumption for traveling has been proposed. However, the power consumption for vehicle-mounted air-conditioner is $30 \%$. It is necessary to calculate the power consumption for both traveling and air-conditioning. In this paper, the authors have constructed a mathematical model which calculates the EV power consumption for both traveling and air-conditioning. The calculated results of this model have been compared to actual traveling data. In addition, factors which have a impact on the EV power consumption have been studied. As a result, the EV power consumption is greately varied by slope resistance, acceleration resistance and required air-conditioning load. Moreover, it is clarified that the air-conditioner consumes approximately $25 \%$ to $50 \%$ of the total power consumption in a hot summer day. In addition, the acceleration and the air-conditioning load differ depending on each vehicle driver. Therefore, in order to evaluate the EV power consumption practically, it is necessary to reflect the characteristics of each vehicle driver.
\end{abstract}

Key words: Electric vehicle, air-conditioner, energy consumption, mathematical model, cruising range.

\section{Introduction}

It is common knowledge that EVs (electric vehicles) have two main functions. One is that EVs are apparatus for locomotion with high energy efficiency [1]. The other is that EVs are apparatus for energy supply. Like the "vehicle to home system", natural energy is charged directly to the EV battery and is supplied to other places without needing to use the power system. In this way, the EV battery is utilized for energy storage, energy transportation and levelling of natural energy output fluctuations [2]. In order to make maximum use of these two functions, it is greatly important to evaluate the remaining battery capacity and the EV power consumption. The remaining battery capacity is evaluated more accurately by combining the following three methods: measurement of the battery voltage, the coulomb counting method integrating the

Corresponding author: Tsuguhiko Nakagawa, professor, research field: thermal engineering. E-mail: nakagawa@cse.oka-pu.ac.jp. charging \& discharging current, and the estimation through the use of the Kalman filter [3, 4]. Moreover, a method to evaluate the EV power consumption has been proposed [5]. In this method, the amount of EV power consumption for traveling is evaluated by a mathematical model which calculates the required power for traveling. However, the power consumption for vehicle-mounted air-conditioner is $30 \%$ [6]. Therefore, it is necessary to construct the mathematical model for both traveling and air-conditioning.

In this paper, the authors have constructed a mathematical model which calculates the EV power consumption for both traveling and air-conditioning. The calculated results of this model have been compared to actual traveling data. In addition, factors which have a great impact on the EV power consumption have been studied.

\section{Evaluation of Remaining Battery Capacity}

The evaluation of the remaining battery capacity is 
important for EV management which is utilized as apparatus for locomotion and energy supply. The commercial EV has the lithium ion battery which has a high energy density. As an example, characteristic of a lithium ion battery is shown in Fig. 1 [7]. In Fig. 1, the remaining battery capacity can be evaluated based on the battery voltage. However, the battery voltage is dependent not only on the remaining battery capacity but also the battery temperature, the amount of discharged electricity and the electrical degradation of the battery. Therefore, it is difficult to evaluate accurately by the battery voltage alone. Another evaluation method is the coulomb counting. In this method, the charging \& discharging current of the battery is integrated over time. In addition, the Kalman filter algorithm which estimates the state of dynamic system through the use of observed value containing error is applied to evaluate the remaining battery capacity. Combining these methods is available to evaluate the remaining battery capacity more accurately. However, in order to make maximum use of EV functions as apparatus for locomotion and energy supply, the evaluation of the EV power consumption is important to manage the energy system using the battery. Therefore, the authors have constructed the mathematical model to calculate the EV power consumption.

\section{Mathematical Model of EV Power Consumption}

EVs consume power for traveling, air-conditioning and accessories such as the car audio system, lamp and so on. The ratio of power consumption for traveling is $60 \%$, air-conditioning is $30 \%$ and accessories are $10 \%$. The total ratio of power consumption for traveling and air-conditioning is $90 \%$. In this study, the mathematical model which calculates the power consumption for traveling and air-conditioning has been constructed as follows.

\subsection{Power Consumption for Traveling}

As shown in Eq. (1), the driving force (in the case

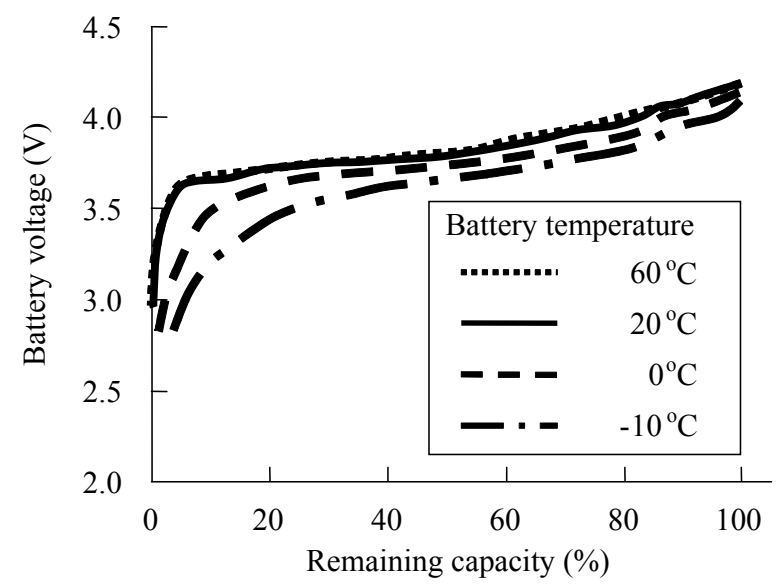

Fig. 1 Characteristic of the lithium ion battery.

that, $F$ is a positive value) and the braking force (in the case that, $F$ is a negative value) are expressed by sum of a wind resistance, a rolling resistance, a slope resistance and an acceleration resistance. As shown in Eq. (2), the wind resistance is proportional to the square of the traveling speed of a vehicle. As shown in Eq. (3), the rolling resistance is proportional to a vehicle weight and is inversely proportional to the slope angle of a road. In this study, the rolling resistance coefficient which is usually varied by the condition of the road and the wheels is the constant value. As shown in Eq. (4), the slope resistance is proportional to the vehicle weight and the slope angle of the road. As shown in Eq. (5), the acceleration resistance is proportional to a vehicle weight, a rotating mass and the acceleration:

$$
\begin{gathered}
\frac{\partial F}{\partial t}=\frac{\partial(F w+F r+F s+F a)}{\partial t} \\
\frac{\partial F w}{\partial t}=\frac{\rho \cdot C d \cdot A}{2} \cdot \frac{\partial v^{2}}{\partial t} \\
\frac{\partial F r}{\partial t}=\mu \cdot M \cdot g \cdot \frac{\partial \cos \theta}{\partial t} \\
\frac{\partial F s}{\partial t}=M \cdot g \cdot \frac{\partial \sin \theta}{\partial t} \\
\frac{\partial F a}{\partial t}=(M+m) \cdot \frac{\partial a}{\partial t}
\end{gathered}
$$


where, $F$ : driving force or braking force $(\mathrm{N}) ; F w$ : wind resistance $(\mathrm{N}) ; F r$ : rolling resistance $(\mathrm{N}) ; F s$ : slope resistance $(\mathrm{N}) ; F a$ : acceleration resistance $(\mathrm{N}) ; v$ : traveling speed of vehicle $(\mathrm{m} / \mathrm{s}) ; a$ : acceleration of vehicle $\left(\mathrm{m} / \mathrm{s}^{2}\right) ; M$ : vehicle weight $(\mathrm{kg}) ; m$ : rotating mass $(\mathrm{kg}) ; \rho$ : density of air $\left(\mathrm{kg} / \mathrm{m}^{3}\right) ; C d$ : drag coefficient (-);A: frontal area of vehicle $\left(\mathrm{m}^{2}\right) ; \mu$ : rolling resistance coefficient $(-) ; g$ : acceleration of gravity $\left(\mathrm{m} / \mathrm{s}^{2}\right) ; \quad \theta$ : slope angle of road $\left({ }^{\circ}\right)$.

In the case that, $F$ is the driving force, EVs consume the power for traveling from the battery. As shown in Eq. (6), the power consumption for traveling is obtained by calculation of resistances which are mentioned above, traveling speed and energy conversion efficiency from the battery to the wheels. In the case that, $F$ is the braking force, EVs take advantage of the energy recovery brake to capture the energy that will be lost. The recovered power by the energy recovery brake is expressed as shown in Eq. (7):

$$
\begin{gathered}
W c=F \cdot v \cdot \frac{1}{\eta_{\mathrm{BAT}}} \cdot \frac{1}{\eta_{\mathrm{INV}}} \cdot \frac{1}{\eta_{\mathrm{MOT}}} \cdot \frac{1}{\eta_{\mathrm{TRA}}} \\
W r g=F \cdot v \cdot \eta_{\mathrm{REC}}
\end{gathered}
$$

where, $W c$ : power consumption for traveling $(\mathrm{W}) ; \mathrm{Wrg}$ : recovered power $(\mathrm{W}) ; \eta_{\mathrm{BAT}}$ : battery charging \& discharging efficiency (-); $\eta_{\mathrm{INv}}$ : inverter efficiency (-); $\eta_{\text {мот }}$ : electric motor efficiency (-); $\eta_{\text {тRА }}$ : power transmission efficiency $(-) ; \eta_{\mathrm{REC}}$ : energy recovery efficiency (-).

\subsection{Power Consumption for Air-Conditioning}

The necessary air-conditioning load to make the inside target temperature is calculated through the use of a heat balance model [8]. A simplified image of the heat balance model is shown in Fig. 2. The heat balance equation is shown in Eq. (8). The amount of heat transferred between the inside and the outside is obtained by using Eqs. (9)-(14). In Eq. (14), $q_{3}$ is heat transfer due to the temperature difference between the inside air and the inside material. The necessary air-conditioning load is calculated by using Eq. (15).

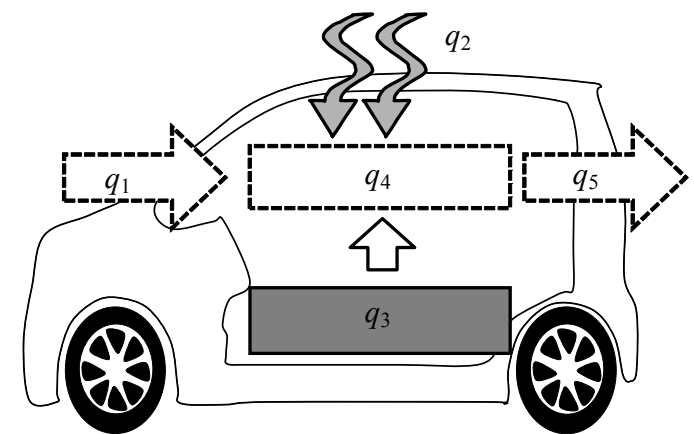

Fig. 2 The heat balance model with cooling.

The power consumption for the air-conditioner is obtained by the necessary load and the coefficient of performance, and energy conversion efficiency. Constraint conditions are shown by Eqs. (16)-(20):

$$
\begin{gathered}
0=\frac{\partial}{\partial \mathrm{t}} \sum_{k=1}^{5} q_{\mathrm{k}} \\
\frac{\partial q_{1}}{\partial t}=u_{1} \cdot A_{1} \cdot c_{p a} \cdot T_{1} \\
\frac{\partial q_{2}}{\partial t}=U_{2} \cdot A_{2} \cdot\left(T_{2}-T_{4}\right) \\
\frac{\partial q_{3}}{\partial t}=M_{3} \cdot c_{p l} \cdot \frac{\partial T_{3}}{\partial t} \\
\frac{\partial q_{4}}{\partial t}=-V_{4} \cdot c_{p a} \cdot \frac{\partial T_{4}}{\partial t} \\
\frac{\partial q_{5}}{\partial t}=-u_{5} \cdot A_{5} \cdot c_{p a} \cdot T_{5} \\
\frac{\partial q_{3}}{\partial t}=U_{3} \cdot A_{3} \cdot\left(T_{3}-T_{4}\right) \\
q_{n}=q_{0}-q_{1}
\end{gathered}
$$

Constraint conditions are shown as follows:

$$
\begin{gathered}
u_{1}=u_{5} \\
A_{1}=A_{5} \\
T_{5}=T_{4} \\
\left.T_{3}\right|_{t=0}=T_{3(0)} \\
\left.T_{4}\right|_{t=0}=T_{4(0)}
\end{gathered}
$$

where, $t$ : elapsed time (s); $q_{0}$ : enthalpy of outside air $(\mathrm{kJ}) ; q_{1}$ : enthalpy of air-conditioner output air $(\mathrm{kJ}) ; q_{2}$ : 
amount of heat transferred from outside $(\mathrm{kJ}) ; q_{3}$ : amount of heat reserving material $(\mathrm{kJ}) ; q_{4}$ : amount of heat reserving inside air $(\mathrm{kJ}) ; q_{5}$ : enthalpy of discharged air to outside $(\mathrm{kJ}) ; q_{n}$ : required capacity of air-conditioner $(\mathrm{kJ}) ; T_{1}$ : air-conditioner output air temperature $(\mathrm{K}) ; T_{2}$ : outside air temperature $(\mathrm{K}) ; T_{3}$ : material temperature $(\mathrm{K}) ; T_{4}$ : inside air temperature (K); $T_{5}$ : discharged air temperature to outside $(\mathrm{K}) ; A_{1}$ : air-conditioner outlet area $\left(\mathrm{m}^{2}\right) ; A_{2}$ : surface area $\left(\mathrm{m}^{2}\right)$; $A_{3}$ : material area $\left(\mathrm{m}^{2}\right) ; A_{5}$ : exhaust port area $\left(\mathrm{m}^{2}\right) ; M_{3}$ : mass of material $(\mathrm{kg}) ; U_{2}$ : total heat transfer coefficient of vehicle $\left(\mathrm{kW} /\left(\mathrm{m}^{2} \cdot \mathrm{K}\right)\right) ; \quad U_{3}$ : total heat transfer coefficient of material $\left(\mathrm{kW} /\left(\mathrm{m}^{2} \cdot \mathrm{K}\right)\right)$; $V_{4}$ : inside volume $\left(\mathrm{m}^{3}\right): u_{1}$ : velocity of air-conditioner output air $(\mathrm{m} / \mathrm{s}) ; u_{5}$ : velocity of discharged air to outside $(\mathrm{m} / \mathrm{s}) ; c_{p a}$ : specific heat of air $\left(\mathrm{kJ} /\left(\mathrm{m}^{3} \cdot \mathrm{K}\right)\right) ; c_{p l}$ : specific heat of material $(\mathrm{kJ} /(\mathrm{kg} \cdot \mathrm{K}))$.

\section{Analysis of EV Power Consumption}

In order to clarify the factors which have a great impact on the EV power consumption, it is necessary to simulate the power consumption under the various traveling conditions. Therefore, the EV power consumption is simulated through the use of the mathematical model which is mentioned above.

\subsection{Simulation Conditions}

In this study, an analysis target vehicle is $\mathrm{i}-\mathrm{MiEV}$ which is manufactured by Mitsubishi Motors Corp.. The conditions for calculation are shown in Table 1. The weight of EV is $1,190 \mathrm{~kg}$ which is the sum of vehicle weight $(1,080 \mathrm{~kg})$ and weight of the people and baggage in the vehicle $(110 \mathrm{~kg})$. The rotating mass is $8 \%$ of the vehicle weight. The electric motor efficiency is dependent on its rotation speed and torque. The maximum motor efficiency is $95 \%$ and the minimum is $85 \%$. The battery charging \& discharging efficiency is 94\% [9]. The DC (direct current) $\Leftrightarrow$ AC (alternative current) conversion efficiency of the inverter is $95 \%$ and the power transmission efficiency is $95 \%$. The energy recovery efficiency is $50 \%$, and the maximum
Table 1 Conditions for calculation.

\begin{tabular}{ll}
\hline Weight of EV & $1,190 \mathrm{~kg}$ \\
Rotating mass & $86.4 \mathrm{~kg}$ \\
Frontal area of vehicle & $1.96 \mathrm{~m}^{2}$ \\
Density of air & $1.205 \mathrm{~kg} / \mathrm{m}^{3}$ \\
Maximum output of electric motor & $30 \mathrm{~kW}$ \\
Battery capacity & $16 \mathrm{kWh}$ \\
Drag coefficient & 0.24 \\
Rolling resistance coefficient & 0.01 \\
\hline
\end{tabular}

power recovery is $30 \mathrm{~kW}$ which is the same as the maximum output of the electric motor. When the traveling speed is reduced below $15 \mathrm{~km} / \mathrm{h}$, the hydraulic brake is used instead of the energy recovery brake [5].

\subsection{Verification of the Mathematical Model}

The calculated results of the mathematical model have been compared to actual traveling data which is published by Mitsubishi Motors Corp. [10]. The traveling condition is the $10-15$ mode which is a typical measuring method of fuel consumption rate in Japan. The air-conditioner is operated under a hot summer day. The outside temperature is $35{ }^{\circ} \mathrm{C}$, relative humidity is $50 \%$ and solar radiation is $0.85 \mathrm{~kW} / \mathrm{m}^{2}$. According to the data from Mitsubishi Motors Corp., the cruising range of $\mathrm{i}-\mathrm{MiEV}$ has $90 \mathrm{~km}$ with the above conditions. The calculated result of the cruising range by the mathematical model is $83 \mathrm{~km}$ with the same conditions. Therefore, the difference between calculated cruising range by the mathematical model and the published data can be obtained within $8 \%$.

\subsection{The EV Power Consumption under Various Traveling Conditions}

In order to clarify factors which have a great impact on the EV power consumption, the following three cases are studied: cruising at a constant speed in a flat suburb area, starting and stopping repeatedly in a flat urban area and climbing \& descending on a sloping road. In addition, in order to focus on the power consumption for traveling, the energy recovery brake is not used and the air-conditioner is not operated in 
following sections. The traveling distance is $4.2 \mathrm{~km}$ which is the same as the traveling conditions of 10-15 mode.

\subsubsection{Cruising at a Constant Speed}

In the case of cruising at a constant speed of $40 \mathrm{~km} / \mathrm{h}$ in a flat suburb area, the breakdown of the power consumption is shown in Fig. 3. According to Fig. 3, the power consumption for the rolling resistance is approximately three times as much as the wind resistance.

\subsubsection{Change of Traveling Speed}

The change of traveling speed while starting and stopping repeatedly in a flat urban area is shown in Fig. 4. The breakdown of the power consumption is shown in Fig. 5. According to Fig. 5, the power consumption for the acceleration resistance is approximately three times as much as the sum of the wind resistance and the rolling resistance. In spite of the same traveling distance, the ratio of the wind resistance and the rolling resistance is different between Fig. 3 and Fig. 5.

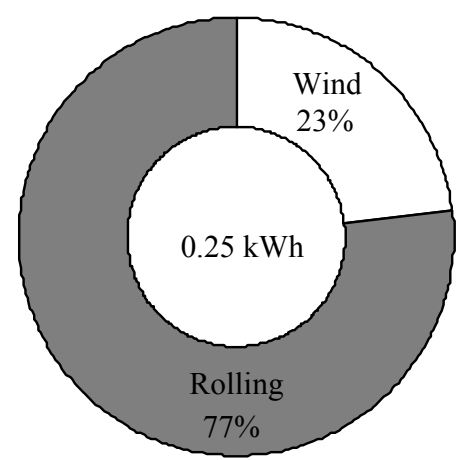

Fig. 3 The breakdown of the power consumption in a flat suburb area.

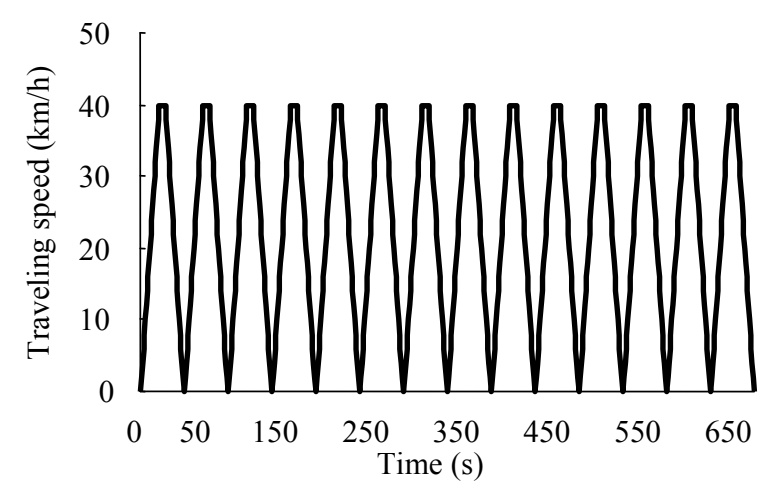

Fig. 4 The change of traveling speed while starting and stopping repeatedly.

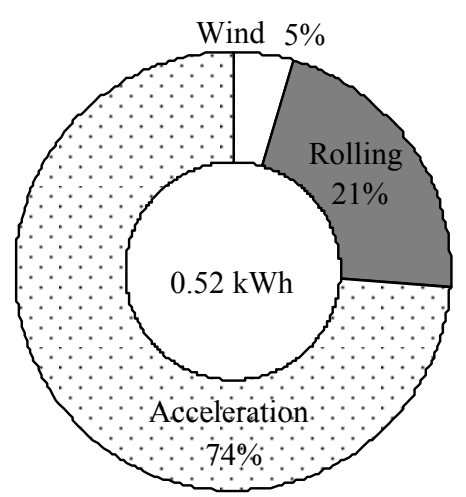

Fig. 5 The breakdown of the power consumption in a flat urban area.

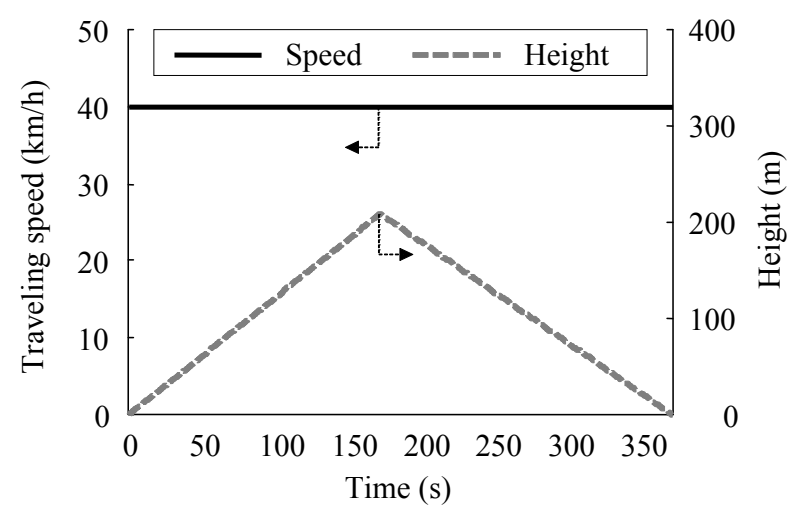

Fig. 6 The change of traveling speed and height.

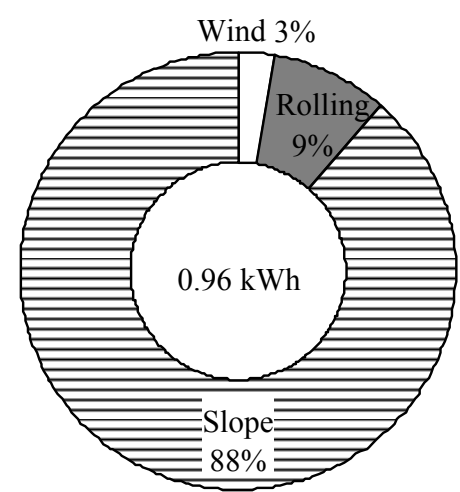

Fig. 7 The breakdown of the power consumption on the sloping road.

This reason is that the average traveling speed is different in each case.

\subsubsection{Climbing \& Descending}

The calculated condition of the climbing $\&$ descending on a sloping road is shown in Fig. 6. In Fig. 6, the traveling speed is constantly $40 \mathrm{~km} / \mathrm{h}$ and the road has a $10 \%$ gradient. The breakdown of the power consumption 
is shown in Fig. 7. According to Fig. 7, the power consumption for the slope resistance is approximately seven times as much as the sum of the wind resistance and the rolling resistance. In addition, in the case of the $20 \%$ gradient, the power consumption is $1.88 \mathrm{kWh}$ which is approximately twice as much as the $10 \%$ gradient.

\subsubsection{The Power Recovery in Each Case}

In this section, the energy recovery brake is used in three cases mentioned above. The power consumption and the power recovery in each case are shown in Fig. 8. As shown in Fig. 8, in the case of climbing and descending on the sloping road, the energy recovery brake can recover $30 \%(=100 \%-0.67 \mathrm{kWh} / 0.96 \mathrm{kWh}$ $\times 100 \%)$ of the power consumption. In the case of starting and stopping repeatedly in the urban area, the energy recovery brake can recover $21 \%(=100 \%-$ $0.41 \mathrm{kWh} / 0.52 \mathrm{kWh} \times 100 \%)$ of the power consumption.

The amount of the actual power consumption is defined as "the amount of power consumption" minus "the amount of power recovery". The actual power consumption on the sloping road is the largest in spite of the power recovery is the largest in three cases. Therefore, it is clarified that EVs consume more power on the sloping road than the flat area.

\subsubsection{Impact of the Air-Conditioner}

In this section, the impact of the air-conditioner is studied. Conditions for the calculation are shown in Table 2. When the inside air temperature reaches the target temperature, the air-conditioner is operated in a constant load which is depended on the outside air condition. The power consumption with operating air-conditioner in three cases mentioned above is shown in Fig. 9. According to Fig. 9, the power consumption for the air-conditioning is the largest in the urban area. As a reason for that, the traveling time is the longest in the urban area and the operating time of the air-conditioner becomes the longest. It is clarified that, the air-conditioner consumes $26 \%(=0.23$ $\mathrm{kWh} / 0.90 \mathrm{kWh} \times 100 \%)$ to $49 \%(=0.40 \mathrm{kWh} / 0.81$

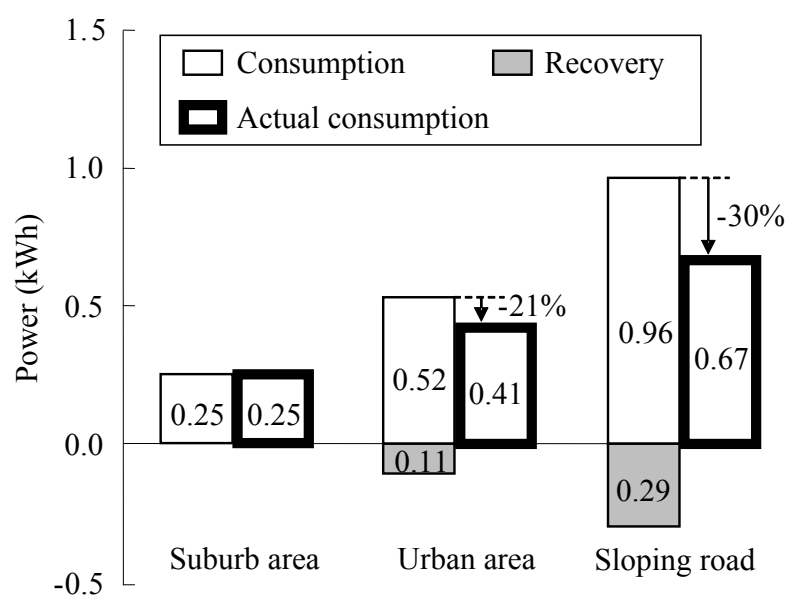

Fig. 8 The power consumption and recovery.

Table 2 Conditions of the air-conditioning.

\begin{tabular}{ll}
\hline Outside temperature & $32{ }^{\circ} \mathrm{C}$ \\
Relative humidity & $60 \%$ \\
Solar radiation & $0.8 \mathrm{~kW} / \mathrm{m}^{2}$ \\
Inside target temperature & $25{ }^{\circ} \mathrm{C}$ \\
Coefficient of performance & 3.1 \\
\hline
\end{tabular}

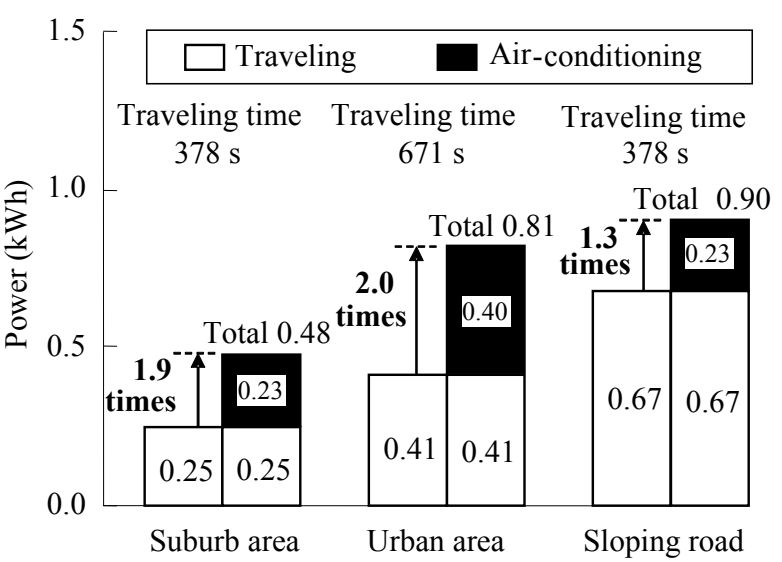

Fig. 9 The EV power consumption with operating the air-conditioner.

$\mathrm{kWh} \times 100 \%$ ) of the total power consumption in a hot summer day. When the air-conditioner is operated, the amount of the power consumption is increased from 1.3 times to 2.0 times. Consequently, the power consumption for air-conditioning is depended on the operation state of the air-conditioner and the traveling time.

The EV power consumption is greatly varied by the slope resistance, the acceleration resistance, and the air-conditioning load. The slope resistance differs 
depending on the topography. The acceleration differs depending on each vehicle driver. If the traveling time is extended, the ratio of the air-conditioning load is increased relatively. The air-conditioning load is changed by setting the inside target temperature which differs for each vehicle driver. Consequently, in order to evaluate the EV power consumption practically, it is necessary to reflect the characteristics of each vehicle driver.

\section{Conclusions}

In this paper, the authors have constructed a mathematical model which calculates the EV power consumption for both traveling and air-conditioning. The calculated results of this model have been compared to actual traveling data. In addition, factors which have a great impact on the EV power consumption have been studied. As a result, the following conclusions have been reached:

- The mathematical model to evaluate the EV power consumption for traveling and air-conditioning, which accounts for $90 \%$ of all the EV power consumption, has been constructed;

- The EV power consumption is greatly varied by the slope resistance, the acceleration resistance, and the required air-conditioning load;

- It is clarified that air-conditioner consumes approximately $25 \%$ to $50 \%$ of the all power consumption in a hot summer day. In addition, the amount of the power consumption is increased from 1.3 times to 2.0 times when the air-conditioner is operated;

- The slope resistance differs depending on the topography. The acceleration differs depending on each vehicle driver. The air-conditioning load is changed by setting the inside target temperature which differs for each vehicle driver. In order to evaluate the EV power consumption practically, it is necessary to reflect the characteristics of each vehicle driver.

\section{References}

[1] U.S. Department of Energy. "All-Electric Vehicles." U.S. Department of Energy. Accessed May 16, 2014. http://www.fueleconomy.gov/feg/evtech.shtml.

[2] Kose, N., and Nakagawa, T. 2013. "Effective Method of Renewable Energy by Using Electric Vehicles and Evaluation by the HEX Model." Journal of Japan Society of Energy and Resources 34 (4): 18-26.

[3] Gregory, L. P. 2004. "Extended Kalman Filtering for Battery Management Systems of LiPB-Based HEV Battery Packs Part 1. Background." Journal of Power Sources 134 (2): 252-61.

[4] Baba, A., and Adachi, S. 2014. "SOC Estimation of HEV/EV Battery Using Series Kalman Filter." Electrical Engineering in Japan 187 (2): 53-62.

[5] Yano, J. 2014. "Estimation of EV Power Consumption and Route Planning Using Probe Data." SEI Technical Review 78 (April): 29-34.

[6] NISSAN Co., Ltd. 2011. "Nissan LEAF PRESS Information.” NISSAN Co., Ltd. Accessed April 20, 2013. http://www.nissan-newsroom.com/COMMON/P.

[7] SANYO Electric Co., Ltd. 2003. "Sanyo Lithium Ion." SANYO Electric Co., Ltd. Accessed May 9, 2014. http://www.rathboneenergy.com/articles/sanyo_lionT_E. pdf.

[8] Notoji, Y., and Nakagawa, T. 2014. "A Novel Concept of AI-EV (Air-conditioner Integrated Electric Vehicle) for the Advanced Smart Community." Journal of Energy and Power Engineering 8 (11): 1933-41.

[9] Nakagawa, T., and Mitsumoto, Y. 2014. "Evaluation of Two-Way Energy System through the Use of PV and EV." Journal of the Japan Institute of Energy 93 (8): 716-24.

[10] Noyama, H., and Umezu, K. 2010. "Air-Conditioning System for Electric Vehicle (i-MiEV)." Presented at the SAE (Society of Automotive Engineers) Automotive Refrigerant \& System Efficiency Symposium 2010, Scottsdale Arizona, USA. 